\title{
Neprilysin inhibition: a new therapeutic option for type 2 diabetes?
}

\author{
Nathalie Esser ${ }^{1,2} \cdot$ Sakeneh Zraika ${ }^{1,2}$ (D) \\ Received: 7 February 2019 / Accepted: 5 April 2019 / Published online: 14 May 2019 \\ (C) Springer-Verlag GmbH Germany, part of Springer Nature 2019
}

\begin{abstract}
Neprilysin is a widely expressed peptidase with broad substrate specificity that preferentially hydrolyses oligopeptide substrates, many of which regulate the cardiovascular, nervous and immune systems. Emerging evidence suggests that neprilysin also hydrolyses peptides that play an important role in glucose metabolism. In recent studies in humans, a dual angiotensin receptor-neprilysin inhibitor (ARNi) improved glycaemic control and insulin sensitivity in individuals with type 2 diabetes and/or obesity. Moreover, preclinical studies have also reported that neprilysin inhibition, alone or in combination with renin-angiotensin system blockers, elicits beneficial effects on glucose homeostasis. Since neprilysin inhibitors have been approved for the treatment of heart failure, their repurposing for treating type 2 diabetes would provide a novel therapeutic strategy. In this review, we evaluate existing evidence from preclinical and clinical studies in which neprilysin is deleted/inhibited, we highlight potential mechanisms underlying the beneficial glycaemic effects of neprilysin inhibition, and discuss possible deleterious effects that may limit the efficacy and safety of neprilysin inhibitors in the clinic. We also review the favourable impact neprilysin inhibition can have on diabetic complications, in addition to glucose control. Finally, we conclude that neprilysin inhibitors may be a useful therapeutic option for treating type 2 diabetes; however, their combination with angiotensin II receptor blockers is needed to circumvent deleterious consequences of neprilysin inhibition alone.
\end{abstract}

Keywords GLP-1 $\cdot$ Insulin resistance $\cdot$ Insulin secretion · Neprilysin $\cdot$ Obesity $\cdot$ Review $\cdot$ Type 2 diabetes

$\begin{array}{ll}\text { Abbreviations } & \\ \text { ANP } & \text { atrial natriuretic peptide } \\ \text { ARB } & \text { angiotensin II receptor blocker } \\ \text { ARNi } & \text { angiotensin receptor-neprilysin inhibitor } \\ \text { BNP } & \text { B-type natriuretic peptide } \\ \text { DPP-4 } & \text { dipeptidyl peptidase-4 } \\ \text { GLP-1 } & \text { glucagon-like peptide-1 } \\ \text { IAPP } & \text { islet amyloid polypeptide } \\ \text { PARADIGM-HF } & \text { Prospective comparison of } \\ & \text { ARNI with ACEI to Determine } \\ & \text { Impact on Global Mortality and } \\ & \text { morbidity in Heart Failure } \\ \text { RAS } & \text { renin-angiotensin system }\end{array}$

Electronic supplementary material The online version of this article (https://doi.org/10.1007/s00125-019-4889-y) contains a slideset of the figures for download, which is available to authorised users.

Sakeneh Zraika

zraikas@uw.edu

1 Veterans Affairs Puget Sound Health Care System, 1660 South Columbian Way (151), Seattle, WA 98108, USA

2 Division of Metabolism, Endocrinology and Nutrition, Department of Medicine, University of Washington, Seattle, WA, USA

\section{Introduction}

There is growing evidence that neprilysin, a ubiquitous peptidase with broad substrate specificity (also referred to as neutral endopeptidase, enkephalinase or EC 3.4.24.11) [1], plays a role in glucose homeostasis. It preferentially hydrolyses oligopeptides by cleaving on the N-terminal side of hydrophobic amino acid residues [1]. Some of its substrates, such as the incretin glucagon-like peptide-1 (GLP-1) [2, 3], natriuretic peptides [4, 5] and bradykinin [5, 6], are known to modulate glucose metabolism [7-10]. Neprilysin activity is increased in plasma and metabolic tissues of mice with diet-induced obesity, and its levels correlate with decreased insulin sensitivity and reduced beta cell function $[11,12]$. In humans, the data are less clear. While there is some evidence that plasma neprilysin levels positively correlate with BMI and other features of the metabolic syndrome in humans $[11,13]$, this needs to be confirmed by additional studies.

Neprilysin inhibitors have been used for decades to treat acute diarrhoea [14] and have also been studied for their blood pressure-lowering, natriuretic and analgesic properties [1]. In both humans [15-17] and animals [3, 18-20], they have also been shown to improve insulin sensitivity, beta cell function and glucose tolerance in diabetic and obese states. Given that 
neprilysin inhibitors are now approved for use in humans with heart failure, a population in which approximately $35 \%$ also have type 2 diabetes [21], it is both timely and important to better understand the molecular mechanisms underpinning their glucoregulatory effects.

In this review, we summarise evidence supporting a beneficial effect of neprilysin inhibition on glucose metabolism, with discussion of potential substrates that may act as mediators (Fig. 1). In studies that found no benefit, we propose potential explanations. We also discuss considerations for the clinical use of neprilysin inhibitors in the prevention and treatment of type 2 diabetes.

\section{Evidence for a beneficial effect of neprilysin inhibition on glucose homeostasis}

The PARADIGM-HF study, a case for the use of neprilysin inhibitors in type 2 diabetes Data from three studies in humans support the use of neprilysin inhibitors in the prevention and treatment of type 2 diabetes [15-17]. All demonstrated beneficial metabolic effects with a combination drug (termed ARNi) comprising the angiotensin II receptor blocker (ARB) valsartan plus the neprilysin inhibitor sacubitril. One study involved a post hoc analysis of patients with type 2 diabetes and heart failure from the Prospective comparison of ARNI with ACEI to Determine Impact on Global Mortality and morbidity in Heart Failure (PARADIGM-HF) trial and showed that treatment with the ARNi for 3 years resulted in greater reduction in $\mathrm{HbA}_{1 \mathrm{c}}$ and fewer patients requiring initiation of oral glucose-lowering medications or insulin therapy, compared with an ACE inhibitor alone [16]. In the second study, treatment of obese hypertensive patients with the ARNi improved insulin sensitivity and lipid mobilisation compared with those treated with amlodipine, a calcium channel blocker [15]. While neither study included a valsartan-alone arm, the use of another drug that inhibits the renin-angiotensin system (RAS), namely, enalapril, as comparator in the PARADIGM-HF study provided data to support the idea that neprilysin inhibition could be a new therapeutic option for type 2 diabetes [16]. That is, the ARNi was superior to the RAS blocker alone, so it is likely

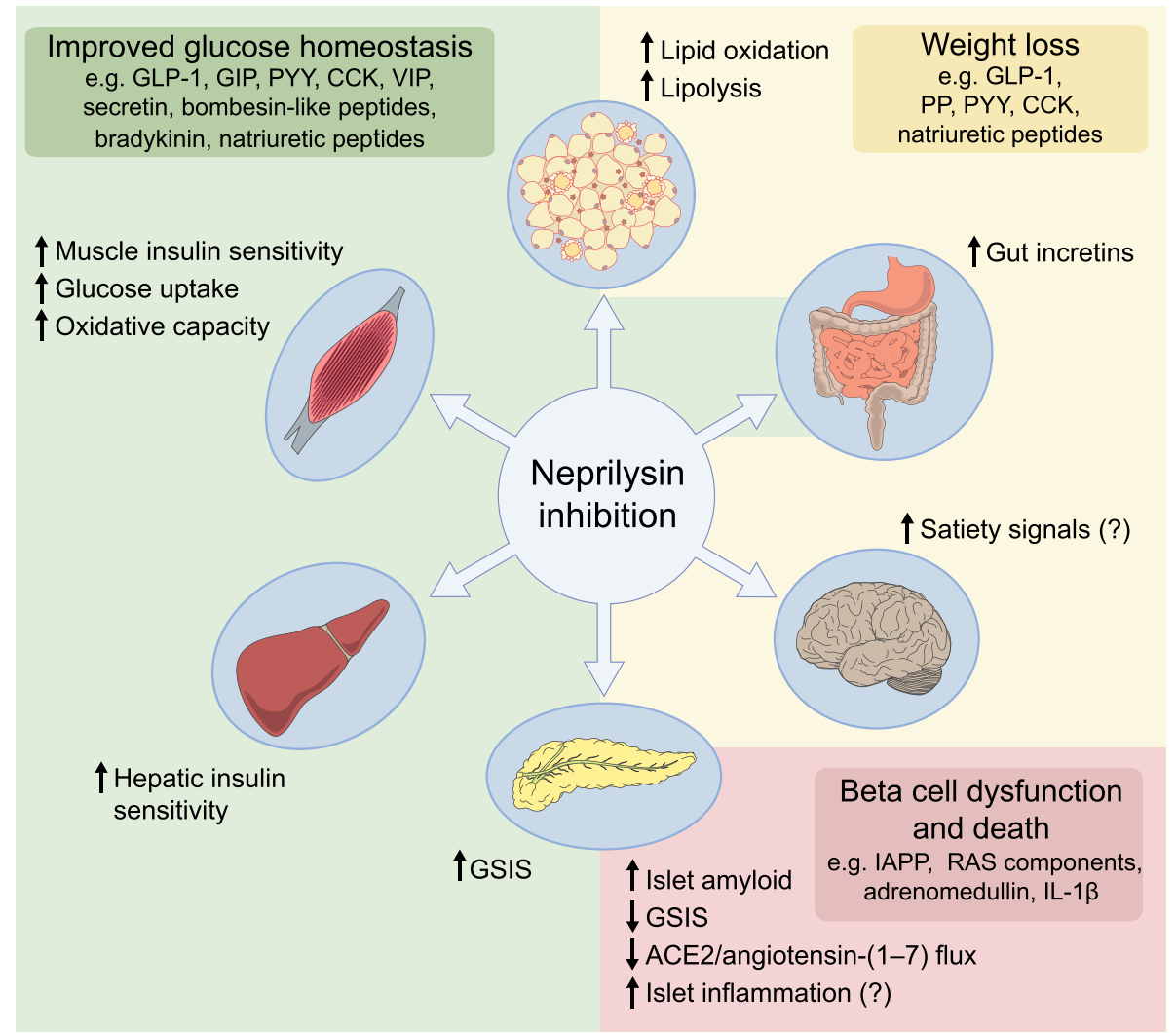

Fig. 1 Effects of reduced neprilysin activity in tissues modulating glucose homeostasis. Neprilysin inhibition improves glucose homeostasis (shaded green) and could induce weight loss (shaded yellow) by increasing levels of several peptides with direct or indirect glucoregulatory properties and anorectic effects. However, neprilysin inhibition may also have detrimental effects in pancreatic islets by increasing levels of substrates that can affect beta cell survival and function or by limiting the ability of angiotensin-(1-7) to promote insulin secretion via its cleavage to angiotensin-(1-2) (shaded pink). The image of the intestine is shaded both yellow and green to indicate that gut incretins impact both glucose homeostasis and body weight. CCK, cholecystokinin; GIP, glucose-dependent insulinotropic peptide; GSIS, glucose-stimulated insulin secretion; PP, pancreatic polypeptide; PYY, peptide YY; VIP, vasoactive intestinal polypeptide. This figure is available as part of a downloadable slideset 
that the added benefit is explained by neprilysin inhibition. Finally, in the third study, among 73 individuals with heart failure, including 16 with diabetes, a change of treatment from either an ACE inhibitor or ARB to ARNi for 3 months resulted in a decrease of plasma neprilysin activity that was associated with reduced fructosamine levels, a marker of protein glycation [17]. This study, together with a previous report [22], suggested that ARNi could exert beneficial effects on glycaemic control, at least in part, by increasing circulating GLP-1 levels. In switching to the ARNi, elevated plasma GLP-1 levels were observed, irrespective of the clinical characteristics of the patients or use of other glucose-lowering medications, which comprised a dipeptidyl peptidase- 4 (DPP-4) inhibitor in some diabetic patients [22]. It is likely that this effect on GLP-1 was mediated by neprilysin inhibition for two reasons: (1) neprilysin is known to cleave and inactivate up to $50 \%$ of the GLP-1 entering the circulation $[2,3]$, and (2) there are no data showing that ARB significantly increases GLP-1 levels.

To date, there are no reports of the metabolic effects of neprilysin inhibitors alone in humans, probably because of the potential harm in elevating neprilysin substrates such as angiotensin II without strategies that can counter their deleterious effects (e.g. RAS blockade; see section below on strategies to negate the potential harmful effects of neprilysin inhibition). Instead, additional insight can be gleaned from preclinical observations with genetic deletion or pharmacological inhibition of neprilysin (Table 1).

\section{Positive impact of neprilysin deficiency or inhibition on glu-} cose homeostasis In isolated pancreatic islets from C57BL/6 mice, pharmacological inhibition of neprilysin increased glucose-stimulated insulin secretion (GSIS) [23]. Also, islets from neprilysin-deficient mice were protected against palmitate-induced insulin secretory dysfunction in vitro [24]. In vivo, we have shown that high-fat-fed neprilysin-deficient mice display improvements in insulin sensitivity, beta cell function and glucose tolerance, as well as beta cell mass expansion $[12,25]$. Furthermore, acute inhibition of neprilysin with subcutaneous or intravenous administration of a pharmacological inhibitor increased insulin secretion and sensitivity in a time- and/or dose-dependent manner in pigs, as well as in lean or obese insulin-resistant rats [3, 18-20] (Table 1). Taken together, these data demonstrate improvements in determinants of glucose tolerance and support the use of neprilysin inhibition to improve the metabolic derangements of type 2 diabetes. However, the molecular mechanisms underlying these beneficial effects remain to be elucidated.

\section{Potential mechanisms by which neprilysin inhibition im-} proves glucose homeostasis Neprilysin is known to degrade multiple peptides that have glucoregulatory properties (see text box). Some studies support a glucose-lowering effect of neprilysin inhibition via increased plasma levels of these substrates, including GLP-1 [3, 12, 17, 22], bradykinin [18, 26] and natriuretic peptides, atrial natriuretic peptide (ANP) and B-type natriuretic peptide (BNP) [27].

One potential mechanism by which neprilysin inhibition improves glucose homeostasis may be by increasing levels, and thereby the insulinotropic effects, of GLP-1 $[2,3]$. This is supported by recent studies in humans treated with ARNi [17, 22], and by observations in animals [12, 23]. We have shown that inhibition of islet neprilysin in vitro enhances both glucose- and GLP-1-mediated insulin secretion in a GLP-1 receptor-dependent manner, raising the possibility that islet neprilysin inhibition improves beta cell function by preserving islet- and/or gut-derived active GLP-1 [23]. Moreover, we demonstrated in vivo in high-fat fed, neprilysin-deficient mice that elevated active GLP-1 levels in plasma were associated with improved glucose tolerance as a result of enhanced beta cell function and insulin sensitivity [12]. Intriguingly, plasma DPP-4 activity was also reduced, suggesting that neprilysin may regulate DPP-4 activity [12]. Indeed, it would be informative to determine whether DPP-4 activity also decreases with pharmacological inhibition of neprilysin in humans.

Plasma levels of bradykinin, another peptide degraded by neprilysin [5, 6], are increased by neprilysin inhibition [28]. Bradykinin modulates glucose metabolism in peripheral tissues by increasing insulin sensitivity $[8,9]$ and two animal studies have suggested that protection of bradykinin from neprilysin-mediated degradation improves insulin action [18, 26].

In obesity, levels of circulating natriuretic peptides are reduced and this predicts the development of type 2 diabetes [10]. In addition to their role in the cardiovascular system, natriuretic peptides exert metabolic effects. ANP promotes lipid mobilisation from adipose tissue, increases postprandial lipid oxidation, induces adiponectin release and reduces adipose tissue inflammation [10]. BNP has similar effects, wherein its administration has been shown to increase insulin sensitivity and decrease blood glucose levels [10]. Thus, raising circulating levels of natriuretic peptides with neprilysin inhibitors $[4,27]$ may protect against glucose intolerance and weight gain, in part by improving lipid mobilisation and oxidation.

In addition to the neprilysin substrates discussed above, neprilysin degrades a number of other peptides that have the potential to modulate glucose metabolism directly or indirectly, including the incretin glucose-dependent insulinotropic peptide (GIP), other gut hormones (cholecystokinin, peptide YY, vasoactive intestinal polypeptide) and pancreatic polypeptide (PP) (see text box). In fact, in mice, coadministration of exogenous PP with the neprilysin inhibitor phosphoramidon resulted in greater plasma PP levels and reduced food intake [29], suggesting that neprilysin inhibition may also have weight-reducing effects. Understanding 


\section{Neprilysin substrates involved in glucose homeostasis and their potential effects on metabolic endpoints}

Substrates

Reported and/or hypothetical metabolic effects of

References neprilysin inhibition

\section{Positive effects}

Bradykinin

Bombesin-like

peptides

CCK

GIP

GLP-1

Natriuretic peptides

(ANP, BNP)

PP

PYY

Secretin

VIP

\section{Negative effects}

Adrenomedullin

Angiotensin II

Angiotensin-(1-7)

Endothelin-1

Glucagon $^{\mathrm{a}}$

IL-1 $\beta$

IAPP

Somatostatin $\uparrow$ Insulin sensitivity

$\uparrow$ Secretion of CCK

$\uparrow$ Satiety

$\uparrow$ GSIS

$\uparrow$ GSIS

$\uparrow$ GSIS

$\downarrow$ Secretion of glucagon

$\uparrow$ Beta cell survival and proliferation

$\uparrow$ Insulin sensitivity

$\downarrow$ Hepatic glucose production

$\downarrow$ Food intake and body weight

$\uparrow$ Insulin sensitivity

$\downarrow$ Adipose tissue inflammation

$\uparrow$ Lipid mobilisation and oxidation

$\downarrow$ Body weight

$\downarrow$ Food intake and body weight

$\uparrow$ Satiety

$\uparrow$ GSIS

$\uparrow$ Satiety

$\uparrow$ GSIS

$\downarrow$ Insulin sensitivity

$\downarrow$ GSIS through $\downarrow$ angiotensin-(1-2)

$\uparrow$ Hepatic glucose production

$\uparrow$ Ketogenesis, lipolysis and proteolysis

$\uparrow$ Beta cell apoptosis

$\downarrow$ Insulin sensitivity

$\downarrow$ GSIS through islet amyloid deposition

$\downarrow$ Secretion of insulin, glucagon and gut hormones

Publications that have shown cleavage of the substrate by neprilysin are referenced

${ }^{a}$ Neprilysin cleaves glucagon in vitro, but changes in endogenous glucagon levels with neprilysin inhibition in vivo are likely to reflect levels of an inactive peptide $[12,27]$

CCK, cholecystokinin; GIP, glucose-dependent insulinotropic peptide; GSIS, glucose-stimulated insulin secretion; PP, pancreatic polypeptide; PYY, peptide YY; VIP, vasoactive intestinal polypeptide 


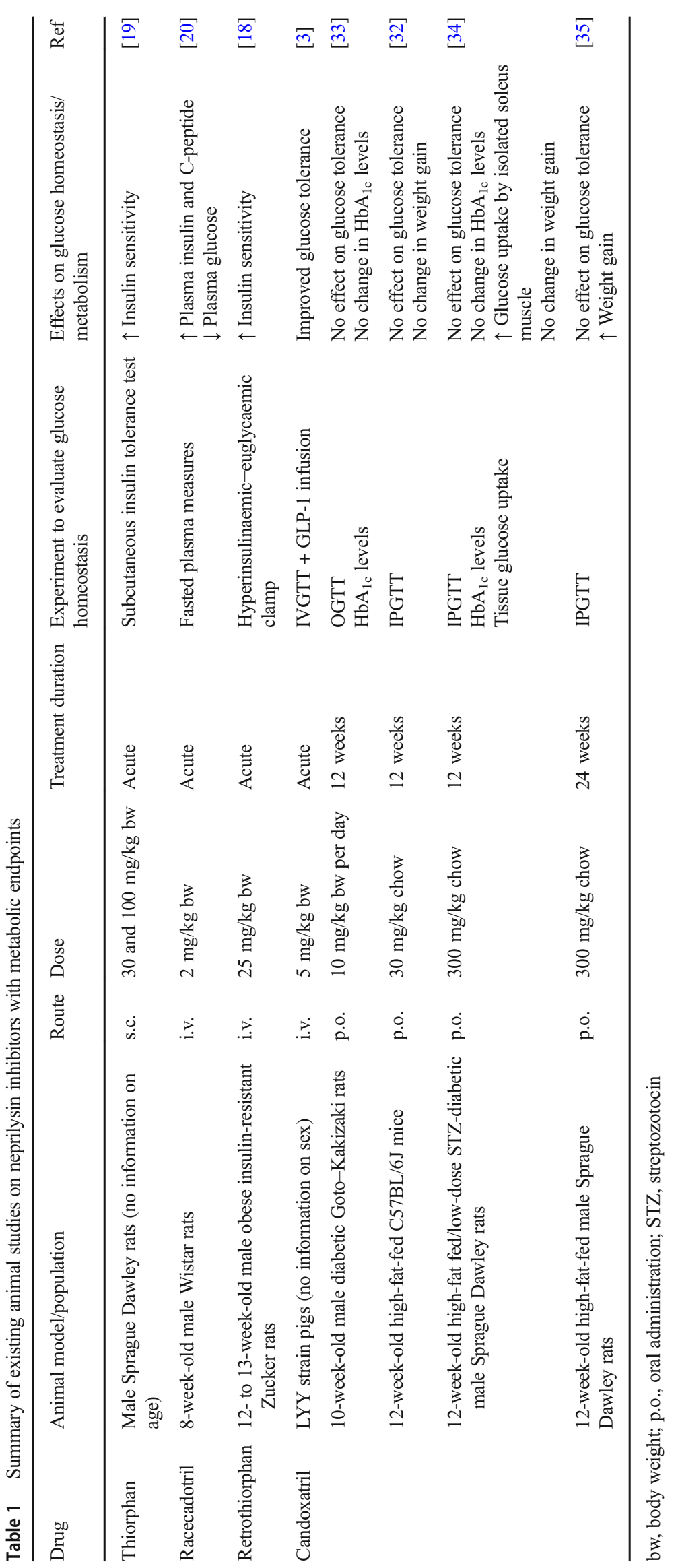




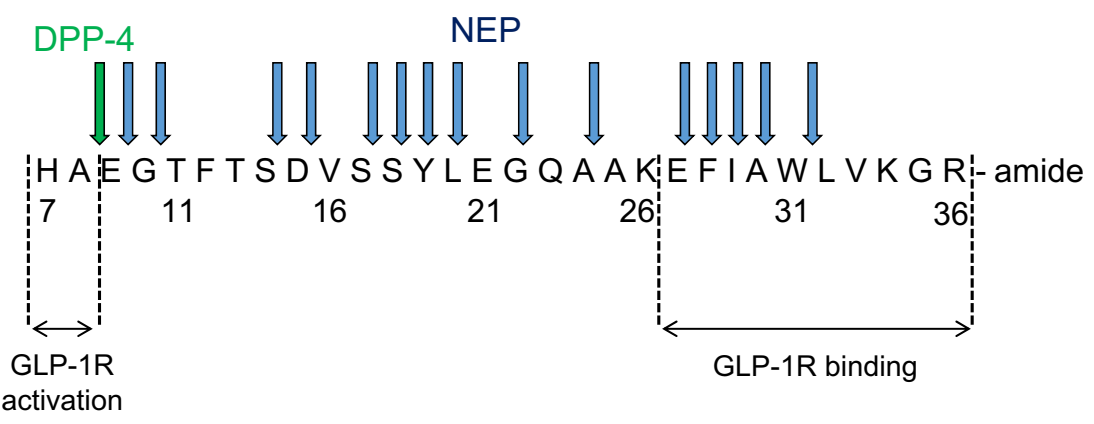

Fig. 2 Amino acid sequence of active GLP-1 showing multiple sites of cleavage by neprilysin (blue arrows) vs the only site of cleavage by DPP4 (green arrow). C-terminal amino acid residues are important for GLP-1 receptor binding, whereas residues 7 and 8 are crucial for GLP-1 receptor activation. The cleavage of GLP-1 by DPP-4 renders the resultant GLP-

1(9-36)amide non-insulinotropic, although GLP-1 receptor binding is still possible. GLP-1 cleavage by neprilysin prevents this binding. GLP$1 \mathrm{R}$, glucagon-like peptide-1 receptor; NEP, neprilysin. This figure is available as part of a downloadable slideset

whether these peptides do in fact modulate glucose homeostasis under conditions of neprilysin deficiency/inhibition is critical if neprilysin inhibitors are to be used to treat type 2 diabetes.

\section{Arguments against a beneficial effect of neprilysin inhibition on glucose homeostasis}

In contrast to the above-mentioned positive effects of reduced neprilysin activity on glucose homeostasis, some studies on deficiency/pharmacological inhibition of neprilysin have raised some uncertainty with respect to the potential glycaemic effects of neprilysin inhibitors [11, 30-35]. Importantly, none of these studies showed detrimental effects on glycaemic status, except one [30]. This latter study reported that 1-year-old neprilysin-deficient mice on regular chow developed impaired oral glucose tolerance; however, the data may have been confounded by selective weight gain resulting from increased food intake [30]. By contrast, in other studies of genetic neprilysin deficiency, lack of neprilysin activity did not alter the susceptibility of mice to high-fat-diet-induced glucose intolerance and insulin resistance [11, 31, 32]. Regarding pharmacological studies in animals, while subcutaneous or intravenous administration of a neprilysin inhibitor for an acute period (up to $2 \mathrm{~h}$ ) [3, 18-20] had a positive impact on glucose homeostasis, its oral administration for a 3 month period (12-14 weeks) failed to improve oral [33] or intraperitoneal $[32,34,35]$ glucose tolerance in high-fat-fed or diabetic rodents, suggesting that either the bioavailability of inhibitor is lower when given orally or compensatory mechanisms are activated over time that result in loss of inhibitor efficacy. Furthermore, studies that employed an intraperitoneal $[32,34,35]$ rather than oral route of glucose administration during the tolerance test would have excluded any effect of neprilysin inhibition to enhance the incretin effect. Thus, it is not possible to draw definitive conclusions in the absence of

further investigations that take into account these considerations.

An important consideration with neprilysin inhibition is that it also increases levels of substrates capable of impairing insulin sensitivity and secretion (see text box), which might be a possible explanation for the negative findings in the studies above. Indeed, adrenomedullin, which increases with neprilysin inhibition [36], impairs glucose tolerance by inhibiting insulin release [37]. Neprilysin is also a component of the RAS, where it cleaves angiotensins I and II and generates the peptides angiotensin-(1-7) [38] and angiotensin-(1-2) [6], both of which have been shown to have glucose-lowering/ insulinotropic effects [39]. In this context, we recently showed that loss of neprilysin activity in murine pancreatic islets prevents the insulinotropic effect of angiotensin-(1-7) [39]. Moreover, neprilysin inhibition alone has been shown to increase angiotensin II levels [28], which may promote insulin resistance and beta cell dysfunction. Together, these finding highlight the complexity of neprilysin inhibition and suggest that monotherapy may not be sufficient to lower glucose levels or may even have some undesirable effects. Also, there may be reduced efficacy when inhibitors are used for prolonged periods.

\section{Considerations for clinical use of neprilysin inhibitors in type 2 diabetes}

Strategies to increase the efficacy of neprilysin inhibitors Combining a neprilysin inhibitor with another glucoselowering agent may achieve a greater therapeutic effect compared with neprilysin inhibition alone. As with other areas of neprilysin research, efforts have so far focused largely on GLP-1-based effects. Since GLP-1 is also a substrate of DPP-4, combining a neprilysin inhibitor with a DPP-4 inhibitor could help improve glucose metabolism. In fact, a study in pigs demonstrated that dual neprilysin and DPP-4 inhibition may have additive effects and therapeutic potential for type 2 
diabetes, as combined neprilysin and DPP-4 inhibition was more effective at maintaining active GLP-1 levels and enhancing insulin secretion than inhibition of either alone [3]. Unlike DPP-4, which cleaves active GLP-1 at a single site to yield truncated GLP-1(9-36)amide, neprilysin degrades both active and truncated GLP-1 at multiple sites [2, 40] (Fig. 2), limiting both GLP-1 receptor binding and activation. Thus, dual inhibition of neprilysin and DPP-4 acts to stabilise and increase the half-life of active GLP-1 [3]. Results from another study suggest that any residual neprilysin activity may negate the beneficial effects of combined neprilysin plus DPP-4 inhibition [33]. That is, when neprilysin activity was reduced by only $40 \%$ in diabetic Goto-Kakizaki rats treated with neprilysin and DPP-4 inhibitors, glycaemic control was not improved [33]. Additional studies, including in humans, are therefore needed to determine whether dual neprilysin and DPP-4 inhibition confers added benefit in terms of glycaemic control.

Importantly, neprilysin also degrades the GLP-1 receptor agonists exendin-4 [2] and liraglutide [41], although both at a much slower rate than native GLP-1. Therefore, evaluation of the effects of neprilysin inhibition in patients treated with GLP-1 analogues is required.

\section{Strategies to negate the potential harmful effects of} neprilysin inhibitors As discussed above, the efficacy of neprilysin inhibitors alone might be limited and/or counterbalanced by elevation of neprilysin substrates that have deleterious effects on glucose homeostasis. Thus, combining neprilysin inhibitors with drugs that can negate these effects is desirable. In fact, this therapeutic rationale was the basis for the development of the ARNi drug for heart failure and hypertension management. Combining neprilysin and RAS inhibition limits the deleterious effects of increased angiotensin II levels caused by neprilysin inhibition, while exploiting beneficial vasodilatory and natriuretic effects resulting from inhibition of natriuretic peptide degradation $[4,17,27]$. Furthermore, studies in humans have demonstrated that combination of a neprilysin inhibitor with a RAS blocker is superior in enhancing glycaemic control vs neprilysin inhibitor alone $[15,16]$. Also, dual ACEneprilysin inhibition in rodents is more effective than inhibition of either ACE [18, 26, 42, 43] or neprilysin [18, 32, 34] alone at improving insulin sensitivity and glucose tolerance, suggesting there is a synergistic or additive effect of combining ACE and neprilysin inhibitors. However, since ACE inhibition also increases bradykinin levels, caution is warranted in considering the clinical use of this combination because of the risk of angioedema [44, 45]. Therefore, use of an ARNi, which inhibits neprilysin and blocks the adverse effects of angiotensin II without bradykinin potentiation, is more favourable. Also, ARNi has already proven to be effective in improving glucose control in obese and type 2 diabetic individuals [15-17].
Given the close association of heart failure with obesity and type 2 diabetes, the use of an ARNi in this specific population is of value because this new drug class offers both improvement in glycaemic control and cardioprotection, while avoiding concomitant use of neprilysin inhibitors with ACE inhibitors.

Beneficial effects of neprilysin inhibition on end-organ damage in type 2 diabetes Beyond its beneficial impact on glycaemic control, neprilysin inhibition could also exert favourable effects in treating diabetic cardiomyopathy, nephropathy, peripheral neuropathy and vasculopathy (reviewed in [46]). In the PARADIGM-HF trial, the ARNi elicited superior cardioprotective [47] and nephroprotective [48] effects compared with RAS inhibition alone, suggesting neprilysin could be a promising therapeutic target for delaying endorgan damage in type 2 diabetes. However, as described above, neprilysin inhibitors could only be administered in combination with RAS blockade to circumvent the potential adverse effects of elevated angiotensin II levels.

\section{Evaluating the safety of long-term neprilysin inhibition Given} that neprilysin has many substrates, evaluating the safety of chronic neprilysin inhibition in humans is critical, particularly with respect to the potential accumulation of amyloid in islets and brain over time.

Neprilysin has been demonstrated to cleave islet amyloid polypeptide (IAPP) [49], the unique peptide constituent of islet amyloid in type 2 diabetes. In humans, aggregated IAPP is associated with beta cell loss [50]. We showed that in amyloid-prone mouse islets, neprilysin inhibition increased amyloid formation and beta cell apoptosis, whereas upregulation of neprilysin had the opposite effect [51]. These data raise the possibility that, despite initially having a positive effect in enhancing insulin release, chronic use of neprilysin inhibitors in patients with type 2 diabetes could promote loss of beta cells, and therefore lead to deterioration of glycaemic status over time. Interestingly, it is also possible that the increase in GLP-1 with neprilysin inhibition may limit islet amyloidinduced beta cell apoptosis [52]. To date, little information exists to address this concern of neprilysin inhibition and islet amyloid in humans, as the PARADIGM-HF trial was short and preclinical studies have all been performed in nonamyloidogenic animal models. Indeed, in contrast to human IAPP, mouse IAPP does not form amyloid [53] and, therefore, human IAPP transgenic mice are required to study islet amyloid. Thus, further work is needed to determine whether sustained neprilysin inhibition increases islet amyloid deposition and induces beta cell dysfunction.

With respect to the potential for neprilysin inhibition to increase amyloid accumulation in the brain, there was no evidence of increased dementia with ARNi treatment in the PARADIGM-HF trial [54]. However, since neprilysin cleaves 
amyloid beta peptide (A $\beta)$ [55], the main component of brain amyloid plaques, some concern has been raised about the possibility of a decline in cognitive function or the development of Alzheimer's disease in patients treated with neprilysin inhibitors over the long term $[56,57]$. This has prompted the US Food and Drug Administration to request further studies that will address this concern [58].

\section{Areas for future work}

To resolve some of the uncertainties in the field with respect to the role of neprilysin in modulating glucose homeostasis, we suggest future work that encompasses the following areas.

More research is needed to elucidate whether substrates that are hydrolysed by neprilysin in vitro (see text box) have clinical relevance with respect to glucose homeostasis in vivo. For example, while there is evidence for neprilysin-mediated degradation of glucagon in vitro [2, 59], studies have suggested that changes in endogenous glucagon levels with neprilysin inhibition in vivo are likely to reflect accumulation of an inactive peptide [3, 60].

In addition to its proteolytic properties, neprilysin can directly bind other proteins via its intracellular domain to mediate effects that are independent of peptide hydrolysis. Very few studies have investigated such protein-protein interactions, despite evidence that insulin signalling molecules, including phosphoinositide 3-kinase, are binding targets [61]. At present, it remains unclear as to whether pharmacological inhibition of neprilysin also alters the protein binding abilities of neprilysin.

It is also unclear how neprilysin action in metabolic tissues aside from the pancreas, such as liver, adipose tissue, kidney and intestine, contributes to regulation of glucose homeostasis. Tissue-specific deletion of neprilysin in rodent models will help delineate the relative importance of the different neprilysin substrates in modulating glucose levels, and aid the development of targeted therapies that avoid undesirable off-target effects.

\section{Conclusion}

There is growing evidence that neprilysin plays a role in glucose homeostasis, wherein its activity in type 2 diabetes and obesity has the potential to negatively impact metabolic processes in various tissues. Thus, by raising levels of several peptides that exert beneficial effects on glucose metabolism, such as GLP-1, natriuretic peptides and bradykinin, inhibition of neprilysin in conditions of nutrient excess could be a powerful strategy to improve glucose homeostasis (Fig. 1). However, because of the action of other enzymes (e.g. DPP4) on neprilysin substrates, resulting in reduced inhibitor efficacy, or the concomitant elevation of neprilysin substrates that can impair insulin sensitivity and beta cell function (Fig. 1 ), the use of combination drugs is a better option than a neprilysin inhibitor alone for treating type 2 diabetes. Moreover, the increase in angiotensin II levels associated with neprilysin inhibition limits its use as monotherapy in type 2 diabetic patients and a neprilysin inhibitor should necessarily be prescribed together with an ARB, which is preferred to an ACE inhibitor to avoid angioedema. In this way, the beneficial glycaemic effects of neprilysin inhibition can be exploited, while limiting harmful side effects of increased angiotensin II levels at the metabolic, cardiovascular and renal levels. Indeed, emerging data from studies in humans using the new ARNi class of medication are compelling [15-17, 47, 48]. Further work is needed to confirm these results, determine if they are sustained over time, and address issues such as longterm safety. In addition, carefully designed and controlled preclinical studies are necessary for understanding the molecular mechanisms by which neprilysin inhibitors work.

Acknowledgements Due to a limit on the number of references allowed, some publications in this field could not be included. However, these additional publications were important in shaping this review; we apologise to those whose work was not cited directly. We thank S.E. Kahn and R.L. Hull (Department of Medicine, University of Washington) for valuable discussions and feedback during the writing of this manuscript.

Funding The authors' work in this area is supported by the Department of Veterans Affairs, VA Puget Sound Health Care System (Seattle, WA, USA), Seattle Institute for Biomedical and Clinical Research (Seattle, WA, USA) and National Institutes of Health grants R01 DK098506 (SZ), P30 DK017047 (University of Washington Diabetes Research Center, Seattle, WA, USA). NE is supported by the Baillet-Latour Fund and the Belgian American Educational Foundation, the Belgian Association of Diabetes, the French Society of Diabetes, the HorlaitDapsens Foundation and the Leon Fredericq Foundation.

Duality of interest SZ receives research support from Novartis Pharmaceuticals Corporation for preclinical studies.

Contribution statement SZ and NE conceived the outline for this review. Both authors reviewed and discussed the relevant literature. NE drafted the review, and both authors revised it critically for important intellectual content. Both authors approved the submitted version.

\section{References}

1. Roques BP, Noble F, Daugé V et al (1993) Neutral endopeptidase 24.11: structure, inhibition, and experimental and clinical pharmacology. Pharmacol Rev 45(1):87-146

2. Hupe-Sodmann K, McGregor GP, Bridenbaugh R et al (1995) Characterisation of the processing by human neutral endopeptidase 24.11 of GLP-1(7-36) amide and comparison of the substrate specificity of the enzyme for other glucagon-like peptides. Regul Pept 58(3):149-156. https://doi.org/10.1016/0167-0115(95)00063-H

3. Plamboeck A, Holst JJ, Carr RD, Deacon CF (2005) Neutral endopeptidase 24.11 and dipeptidyl peptidase IV are both mediators of 
the degradation of glucagon-like peptide 1 in the anaesthetised pig. Diabetologia 48(9):1882-1890. https://doi.org/10.1007/s00125005-1847-7

4. Kenny AJ, Bourne A, Ingram J (1993) Hydrolysis of human and pig brain natriuretic peptides, urodilatin, C-type natriuretic peptide and some C-receptor ligands by endopeptidase-24.11. Biochem J 291(1):83-88. https://doi.org/10.1042/bj2910083

5. González W, Soleilhac JM, Fournié-Zaluski MC et al (1998) Characterization of neutral endopeptidase in vascular cells, modulation of vasoactive peptide levels. Eur J Pharmacol 345(3):323331. https://doi.org/10.1016/S0014-2999(98)00038-7

6. Gafford JT, Skidgel RA, Erdos EG, Hersh LB (1983) Human kidney "enkephalinase", a neutral metalloendopeptidase that cleaves active peptides. Biochemistry 22(13):3265-3271. https://doi.org/ 10.1021/bi00282a035

7. Orskov C (1992) Glucagon-like peptide-1, a new hormone of the entero-insular axis. Diabetologia 35(8):701-711

8. Mori MA, Sales VM, Motta FL et al (2012) Kinin B1 receptor in adipocytes regulates glucose tolerance and predisposition to obesity. PLoS One 7(9):e44782. https://doi.org/10.1371/journal.pone. 0044782

9. Henriksen EJ, Jacob S, Fogt DL, Dietze GJ (1998) Effect of chronic bradykinin administration on insulin action in an animal model of insulin resistance. Am J Phys 275:R40-R45

10. Moro C (2016) Targeting cardiac natriuretic peptides in the therapy of diabetes and obesity. Expert Opin Ther Targets 20(12):14451452. https://doi.org/10.1080/14728222.2016.1254198

11. Standeven KF, Hess K, Carter AM et al (2011) Neprilysin, obesity and the metabolic syndrome. Int J Obes 35(8):1031-1040. https:// doi.org/10.1038/ijo.2010.227

12. Willard JR, Barrow BM, Zraika S (2017) Improved glycaemia in high-fat-fed neprilysin-deficient mice is associated with reduced DPP-4 activity and increased active GLP-1 levels. Diabetologia 60(4):701-708. https://doi.org/10.1007/s00125-016-4172-4

13. Rice GI, Jones AL, Grant PJ et al (2006) Circulating activities of angiotensin-converting enzyme, its homolog, angiotensinconverting enzyme 2 , and neprilysin in a family study. Hypertension 48(5):914-920. https://doi.org/10.1161/01.HYP. 0000244543.91937 .79

14. Salazar-Lindo E, Santisteban-Ponce J, Chea-Woo E, Gutierrez M (2000) Racecadotril in the treatment of acute watery diarrhea in children. N Engl J Med 343(7):463-467. https://doi.org/10.1056/ NEJM200008173430703

15. Jordan J, Stinkens R, Jax T et al (2017) Improved insulin sensitivity with angiotensin receptor neprilysin inhibition in individuals with obesity and hypertension. Clin Pharmacol Ther 101(2):254-263. https://doi.org/10.1002/cpt.455

16. Seferovic JP, Claggett B, Seidelmann SB et al (2017) Effect of sacubitril/valsartan versus enalapril on glycaemic control in patients with heart failure and diabetes: a post-hoc analysis from the PARADIGM-HF trial. Lancet Diabetes Endocrinol 5(5):333-340. https://doi.org/10.1016/S2213-8587(17)30087-6

17. Nougué H, Pezel T, Picard F et al (2018) Effects of sacubitril/ valsartan on neprilysin targets and the metabolism of natriuretic peptides in chronic heart failure: a mechanistic clinical study. Eur J Heart Fail. https://doi.org/10.1002/ejhf.1342

18. Arbin V, Claperon N, Fournié-Zaluski MC et al (2001) Acute effect of the dual angiotensin-converting enzyme and neutral endopeptidase 24-11 inhibitor mixanpril on insulin sensitivity in obese Zucker rat. Br J Pharmacol 133(4):495-502. https://doi.org/10. 1038/sj.bjp.0704098

19. Chipkin RE, Kreutner W, Billard W (1984) Potentiation of the hypoglycemic effect of insulin by thiorphan, an enkephalinase inhibitor. Eur J Pharmacol 102(1):151-154. https://doi.org/10.1016/ 0014-2999(84)90349-2
20. Wu HT, Chang CK, Cheng KC et al (2010) Increase of plasma insulin by racecadotril, an inhibitor of enkephalinase, in Wistar rats. Horm Metab Res 42(04):261-267. https://doi.org/10.1055/s-00291246190

21. Kristensen SL, Preiss D, Jhund PS et al (2016) Risk related to prediabetes mellitus and diabetes mellitus in heart failure with reduced ejection fraction. Circ Heart Fail 9:e002560

22. Vodovar N, Nougué H, Launay JM et al (2017) Sacubitril/valsartan in PARADIGM-HF. Lancet Diabetes Endocrinol 5(7):495-496. https://doi.org/10.1016/S2213-8587(17)30177-8

23. Esser N, Barrow BM, Choung E et al (2018) Neprilysin inhibition in mouse islets enhances insulin secretion in a GLP-1 receptor dependent manner. Islets 10(5):175-180. https://doi.org/10.1080/ 19382014.2018.1502521

24. Zraika S, Koh DS, Barrow BM et al (2013) Neprilysin deficiency protects against fat-induced insulin secretory dysfunction by maintaining calcium influx. Diabetes 62(5):1593-1601. https://doi.org/ $10.2337 / \mathrm{db} 11-1593$

25. Parilla JH, Hull RL, Zraika S (2018) Neprilysin deficiency is associated with expansion of islet $\beta$-cell mass in high fat-fed mice. $\mathrm{J}$ Histochem Cytochem 66(7):523-530. https://doi.org/10.1369/ 0022155418765164

26. Wang CH, Leung N, Lapointe N et al (2003) Vasopeptidase inhibitor omapatrilat induces profound insulin sensitization and increases myocardial glucose uptake in Zucker fatty rats. Circulation 107(14): 1923-1929. https://doi.org/10.1161/01.CIR.0000062646.09566. CC

27. Northridge D, Alabaster C, Connell JC et al (1989) Effects of UK 69 578: a novel atriopeptidase inhibitor. Lancet 334(8663):591593. https://doi.org/10.1016/S0140-6736(89)90714-9

28. Campbell DJ, Anastasopoulos F, Duncan AM et al (1998) Effects of neutral endopeptidase inhibition and combined angiotensin converting enzyme and neutral endopeptidase inhibition on angiotensin and bradykinin peptides in rats. J Pharmacol Exp Ther 287(2):567-577

29. Cuenco J, Minnion J, Tan T et al (2017) Degradation paradigm of the gut hormone, pancreatic polypeptide, by hepatic and renal peptidases. Endocrinology 158(6):1755-1765. https://doi.org/10.1210/ en.2016-1827

30. Becker M, Siems W-E, Kluge R et al (2010) New function for an old enzyme: NEP deficient mice develop late-onset obesity. PLoS One 5(9):e12793. https://doi.org/10.1371/journal.pone.0012793

31. Davidson E, Coppey L, Lu B et al (2009) The roles of streptozotocin neurotoxicity and neutral endopeptidase in murine experimental diabetic neuropathy. Exp Diabetes Res 2009:431980

32. Coppey L, Lu B, Gerard C, Yorek MA (2012) Effect of inhibition of angiotensin-converting enzyme and/or neutral endopeptidase on neuropathy in high-fat-fed C57B1/6J mice. J Obes 2012:326806

33. Simonsen L, Pilgaard S, Carr RD et al (2009) Inhibition of neutral endopeptidase 24.11 does not potentiate the improvement in glycemic control obtained with dipeptidyl peptidase-4 inhibition in diabetic Goto-Kakizaki rats. Horm Metab Res 41(11):851-853. https://doi.org/10.1055/s-0029-1225609

34. Davidson EP, Coppey LJ, Holmes A, Yorek MA (2012) Effect of inhibition of angiotensin converting enzyme and/or neutral endopeptidase on vascular and neural complications in high fat fed/low dose streptozotocin-diabetic rats. Eur J Pharmacol 677(1-3):180 187. https://doi.org/10.1016/j.ejphar.2011.12.003

35. Davidson EP, Coppey LJ, Dake B, Yorek MA (2011) Effect of treatment of Sprague Dawley rats with AVE7688, enalapril, or candoxatril on diet-induced obesity. J Obes 2011:686952

36. Lisy O, Jougasaki M, Schirger JA et al (1998) Neutral endopeptidase inhibition potentiates the natriuretic actions of adrenomedullin. Am J Physiol Ren Physiol 275(3):F410-F414. https://doi.org/10. 1152/ajprenal.1998.275.3.F410 
37. Martínez A, Weaver C, López J et al (1996) Regulation of insulin secretion and blood glucose metabolism by adrenomedullin. Endocrinology 137(6):2626-2632. https://doi.org/10.1210/endo. 137.6.8641217

38. Rice GI, Thomas DA, Grant PJ et al (2004) Evaluation of angiotensin-converting enzyme (ACE), its homologue ACE2 and neprilysin in angiotensin peptide metabolism. Biochem J 383(1): 45-51. https://doi.org/10.1042/BJ20040634

39. Brar GS, Barrow BM, Watson $\mathrm{M}$ et al (2017) Neprilysin is required for angiotensin-(1-7)'s ability to enhance insulin secretion via its proteolytic activity to generate angiotensin-(1-2). Diabetes 66(8): 2201-2212. https://doi.org/10.2337/db16-1318

40. Windeløv JA, Albrechtsen NJ, Kuhre RE et al (2017) Why is it so difficult to measure glucagon-like peptide-1 in a mouse? Diabetologia 60(10):2066-2075. https://doi.org/10.1007/s00125017-4347-7

41. Malm-Erjefält M, Bjørnsdottir I, Vanggaard J et al (2010) Metabolism and excretion of the once-daily human glucagon-like peptide- 1 analog liraglutide in healthy male subjects and its in vitro degradation by dipeptidyl peptidase IV and neutral endopeptidase. Drug Metab Dispos 38(11):1944-1953. https://doi.org/10.1124/ dmd. 110.034066

42. Aguilar-Salinas CA, Arellano SA, Villanueva-Sanchez O et al (2001) Effects of omapatrilat on blood pressure and insulin sensitivity in an animal model of insulin resistance. Blood Press 10(3): 164-169. https://doi.org/10.1080/080370501753182389

43. Arbin V, Claperon N, Fournié-Zaluski MC et al (2003) Effects of dual angiotensin-converting enzyme and neutral endopeptidase 2411 chronic inhibition by mixanpril on insulin sensitivity in lean and obese Zucker rats. J Cardiovasc Pharmacol 41(2):254-264. https:// doi.org/10.1097/00005344-200302000-00015

44. Kostis JB, Packer M, Black HR et al (2004) Omapatrilat and enalapril in patients with hypertension: the Omapatrilat Cardiovascular Treatment vs. Enalapril (OCTAVE) trial. Am J Hypertens 17(2): 103-111. https://doi.org/10.1016/j.amjhyper.2003.09.014

45. Messerli FH, Nussberger J (2000) Vasopeptidase inhibition and angio-oedema. Lancet 356(9230):608-609. https://doi.org/10. 1016/S0140-6736(00)02596-4

46. Malek V, Gaikwad AB (2017) Neprilysin inhibitors: a new hope to halt the diabetic cardiovascular and renal complications? Biomed Pharmacother 90:752-759. https://doi.org/10.1016/j.biopha.2017. 04.024

47. McMurray JJ, Packer M, Desai AS et al (2014) Angiotensinneprilysin inhibition versus enalapril in heart failure. N Engl $\mathrm{J}$ Med 371(11):993-1004. https://doi.org/10.1056/NEJMoa1409077

48. Packer M, Claggett B, Lefkowitz MP et al (2018) Effect of neprilysin inhibition on renal function in patients with type 2 diabetes and chronic heart failure who are receiving target doses of inhibitors of the renin-angiotensin system: a secondary analysis of the PARADIGM-HF trial. Lancet Diabetes Endocrinol 6(7):547554. https://doi.org/10.1016/S2213-8587(18)30100-1

49. Guan H, Chow KM, Shah R et al (2012) Degradation of islet amyloid polypeptide by neprilysin. Diabetologia 55(11):2989-2998. https://doi.org/10.1007/s00125-012-2678-y

50. Jurgens CA, Toukatly MN, Fligner CL et al (2011) $\beta$-cell loss and $\beta$-cell apoptosis in human type 2 diabetes are related to islet amyloid deposition. Am J Pathol 178(6):2632-2640. https://doi.org/10. 1016/j.ajpath.2011.02.036

51. Zraika S, Aston-Mourney K, Marek P et al (2010) Neprilysin impedes islet amyloid formation by inhibition of fibril formation rather than peptide degradation. J Biol Chem 285(24):18177-18183. https://doi.org/10.1074/jbc.M109.082032

52. Aston-Mourney K, Hull RL, Zraika S et al (2011) Exendin-4 increases islet amyloid deposition but offsets the resultant beta cell toxicity in human islet amyloid polypeptide transgenic mouse islets. Diabetologia 54(7):1756-1765. https://doi.org/10.1007/s00125011-2143-3

53. Westermark P, Engström U, Johnson KH et al (1990) Islet amyloid polypeptide: pinpointing amino acid residues linked to amyloid fibril formation. Proc Natl Acad Sci 87(13):5036-5040. https:// doi.org/10.1073/pnas.87.13.5036

54. Cannon JA, Shen L, Jhund PS et al (2017) Dementia-related adverse events in PARADIGM-HF and other trials in heart failure with reduced ejection fraction. Eur J Heart Fail 19(1):129-137. https://doi.org/10.1002/ejhf.687

55. Iwata N, Tsubuki S, Takaki Y et al (2000) Identification of the major $\mathrm{A} \beta_{1-42}$-degrading catabolic pathway in brain parenchyma: suppression leads to biochemical and pathological deposition. Nat Med 6(2):143-150. https://doi.org/10.1038/72237

56. Campbell DJ (2017) Long-term neprilysin inhibition - implications for ARNIs. Nat Rev Cardiol 14(3):171-186. https://doi.org/10. 1038/nrcardio.2016.200

57. Feldman AM (2016) Neprilysin inhibition in the time of precision medicine. JACC Heart Fail. pii:S2213-1779(16)30049-X

58. U.S. Food and Drug Administration (2015) New drug application approval letter. Available from http://www.accessdata.fda.gov/ drugsatfda_docs/appletter/2015/207620Orig1s0001tr.pdf Accessed November 30, 2015

59. Kerr MA, Kenny AJ (1974) The purification and specificity of a neutral endopeptidase from rabbit kidney brush border. Biochem J 137(3):477-488. https://doi.org/10.1042/bj1370477

60. Trebbien R, Klarskov L, Olesen M et al (2004) Neutral endopeptidase 24.11 is important for the degradation of both endogenous and exogenous glucagon in anesthetized pigs. Am J Physiol Endocrinol Metab 287(3):E431-E438. https://doi.org/10.1152/ajpendo.00353. 2003

61. Shen R, Milowsky MI, Ozaki N et al (2002) Detection of the p110 beta subunit of phosphatidylinositol 3-kinase complexed with neutral endopeptidase. Anticancer Res 22(5):2533-2538

62. Shipp MA, Tarr GE, Chen CY et al (1991) CD10/neutral endopeptidase 24.11 hydrolyzes bombesin-like peptides and regulates the growth of small cell carcinomas of the lung. Proc Natl Acad Sci U S A 88(23):10662-10666. https://doi.org/10.1073/pnas.88.23.10662

63. Deschodt-Lanckman M, Strosberg AD (1983) In vitro degradation of the C-terminal octapeptide of cholecystokinin by 'enkephalinase A'. FEBS Lett 152(1):109-113. https://doi.org/10.1016/00145793(83)80493-1

64. Medeiros MD, Turner AJ (1994) Processing and metabolism of peptide-YY: pivotal roles of dipeptidylpeptidase-IV, aminopeptidase-P, and endopeptidase-24.11. Endocrinology 134(5):20882094. https://doi.org/10.1210/endo.134.5.7908871

65. Skolovsky M, Galron R, Kloog Y et al (1990) Endothelins are more sensitive than sarafotoxins to neutral endopeptidase: possible physiological significance. Proc Natl Acad Sci U S A 87(12):47024706. https://doi.org/10.1073/pnas.87.12.4702

66. Pierart ME, Najdovski T, Appelboom TE, Deschodt-Lanckman MM (1988) Effect of human endopeptidase 24.11 ("enkephalinase") on IL-1-induced thymocyte proliferation activity. J Immunol 140:3808-3811

67. Sakurada C, Yokosawa H, Ishii S (1990) The degradation of somatostatin by synaptic membrane of rat hippocampus is initiated by endopeptidase-24.11. Peptides 11(2):287-292. https://doi.org/10. 1016/0196-9781(90)90084-I

Publisher's note Springer Nature remains neutral with regard to jurisdictional claims in published maps and institutional affiliations. 